\title{
Hybrid Multi-Criteria Decision Making Approach to Ranking COVID-19 Vaccines
}

\author{
Randa Mohamed \\ Assistant Lecturer, \\ Faculty of Computers and \\ Information, \\ South Valley University, Qena \\ 83523, Egypt
}

\author{
Amal Rashed \\ Lecturer, \\ Faculty of Computers and \\ Information, \\ South Valley University, Qena \\ 83523, Egypt
}

\author{
Doaa Mohamed \\ Research Assistant, \\ Faculty of Engineering, \\ Assiut University, Asyut Egypt
}

\begin{abstract}
The coronavirus is influencing more than 219 countries and territories. A coronavirus is a type of virus, there are many kinds, and some cause disease. A coronavirus identified in 2019, SARS-CoV-2, has affected a pandemic of respiratory illness, called COVID-19. The whole world is seeking to manufacture vaccines to curb this epidemic. Vaccination is a harmless and active way to elude disease and save lives. Without vaccines, we are at risk of thoughtful disease and disability from diseases like measles, meningitis, pneumonia, tetanus, and polio. Many of these diseases can be lifethreatening. World Health Organization(WHO) evaluates that vaccines protect between 2 and 3 million lives every year. There are three COVID-19 vaccines for which certain national regulatory authorities have authorized the use. In this paper we use Multi-criteria decision analysis (MCDA) hybrid technique to analysis and compare between three COVID-19 vaccines to select the best. We combine three Multi criteria decision (MCD methods. Three methods are Simple Additive Weighting (SAW), the Technique for Order or Preference by Similarity to Ideal Solution (TOPSIS) and Analytic Hierarchy Process (AHP), to classify the vaccines, after analysis three vaccines using MCD methods the result show the result shows that the order of vaccines are Pfizer then Johnson \& Johnson's then AstraZeneca/Oxford
\end{abstract}

\section{Keywords}

Vaccines, multi criteria making decision, AHP, SWA, TOPSIS, MCDA

\section{INTRODUCTION}

The fast spread of the COVID-19 virus around the world poses a real threat to public safety. A great number of infections and the high spread of COVID-19 around the world confirms that the virus is transmitted through carriers or between people, which poses a serious challenge to manage its spread [1] Finding a fitting vaccine for Coronavirus has become the world's goal now to decrease infection with this fierce virus and preserve the lives of people. Clinical trials for all vaccines must first display that they are effective and safe before any vaccine can certified or agreed for use there are now several vaccines that are in use WHO issued [2] Use Listing (EULs) for the Pfizer COVID-19 vaccine (BNT162b2) on 31 December 2020. On 15 February 2021, WHO issued EULs for two versions of the AstraZeneca/Oxford COVID-19 vaccine, manufactured by the Serum Institute of India and SKBio. On 12 March 2021, WHO issued an EUL for the COVID-19 vaccine Johnson \& Johnson's, developed by Janssen (Johnson \& Johnson). COVID-19 is considered a catastrophic global healthcare problem that contains respiratory, hepatic, gastrointestinal and neurological complications. Like common epidemiologic diseases, fighting the spread of the novel COVID-19 virus is a complex mission and needs coordinated efforts by public healthcare authorities. COVID-19 was produced by SARS-CoV-2 virus. A big number of infections and the high speed of spread of COVID19 around the world approves that the virus is transferred through carriers or between people, which fakes a serious challenge to control its spread. [3,4,5] Therefore, various comprehensive preventive measures such as social distancing have to be taken worldwide to decrease the spread of infection. However, the ultimate measure to end the coronavirus pandemic is the creation of an effective vaccine. Experts and governments recognize that a vaccine may not be ready before 2 years, and this is not an inevitability. Therefore, an effective and immediate prevention mechanism must be adopted until a vaccine is developed. Decision making in healthcare involves a complex set of pragmatic interactions among many stakeholders [6] Limited mathematical models or techniques are currently used to support the selection of a suitable vaccine for fighting pandemics/epidemics. There is a lack of literature regarding factors that could lead to the acceptance or rejection of a vaccine among vaccine alternatives. The analytic hierarchy process (AHP) was introduced in 1980 [7] to help resolve decision-making issues and prioritize decision alternatives. It had been widely used in decision-making systems in different fields since then to help solve various problems [8-14] Recently, researchers used AHP in healthcare and medical sectors to support decisionmaking. For example, health intervention option was evaluated and analyzed for basic scoring using AHP [15].

Multi-criteria decision-making (MCDM) methods contain a different set of methods. These approaches can be generally divided into two types: discrete MCDM or discrete multiattribute decision-making (MADM) and continuous multiobjective decision-making (MODM) methods [16,17]. The development of MCDM research made momentum in the 1980 s and early 1990s and seems to have continued to grow exponentially up to the present time [18] [19] has made the basics of decision-making with multiple objectives. In this paper, multiple decision-making approaches design and develop to help to a ranking available vaccine for COVID- 19 . MCDM technique is a portion of a common class of Operations Research models. MCDM methods can simply and successfully solve the evaluation and selection problems, which are complex and have multiple conflicting criteria or objectives. In many real-life decision-making problems [20] we use the MCDM method to estimate the finest alternative. In this paper, we use Three techniques, Simple Additive Weighting (SAW), the Technique for Order of Preference by 
Similarity to Ideal Solution (TOPSIS) and Analytic Hierarchy Process (AHP), Through the use of MCDM the criteria methods will be weighted to estimate vaccines. Analysis and calculation of the weights of these factors will be directed using Analytic Hierarchy Process (AHP). The assessment of the alternatives according to their degree of adequacy is carried out through the TOPSIS method (Technique for Order Preference by Similarity to Ideal Solution). And Simple Additive Weighting (SAW), the study consists of four sections.

Literature reviews are given in the Introduction section. In section 2 the proposed method is examined and methods will be discussed. In section 3 experimental result is presented to illustrate the proposed method. Finally, conclusions

\section{RELATED WORK}

Decision-making methods show good performance and good accuracy in many applications. [20] Dhiman applied three methods, (i) Simple Additive Weighting (SAW), (ii) the Technique for Order of Preference by Similarity to Ideal Solution (TOPSIS) and (iii) Complex Proportional Assessment (COPRAS) to identify the best alternative in energy sources have gained much importance owing to their clean operation. With restricted petroleum product and atomic assets, sun oriented and wind energy advancements have grown out of their piece of the overall industry. Given its rich maintainability, a renewable energy power portfolio reinforces the strength of a country's economy separately from its positive environmental impact, wind energy has also made the job opportunities universally. With enlarged penetration of renewable energy sources, its operation, and control have become important. Suner [21] applied AHP to define the most appropriate method for building of a sequential decision tree in managing rectal cancer. AHP, TOPSIS, ELECTRE, GRA, and SAW use in the supply chain, supplier evaluation and selection problem is one of the greatest studied subjects because of the significant roles of suppliers in terms of the chain's sustainability and profitability. Organizations need to adopt a systematic method to estimate and choice the finest supplier according to their corresponding criteria in today's competitive environment. A lot of applications of supplier evaluation and selection can be seen in the lit, written reports in the health-care sector are insufficient. Hospitals in the healthcare area also have to consider their supplier-related determination to lessening risks and screw thread which affect their effectiveness [22] providing different hybrid models for selecting the best supplier for hospitals. The analytic hierarchy process (AHP) method is deployed to the weight unit the criteria and suppliers are listed via proficiency for order preference by similarity to ideal solution (TOPSIS), elimination and choice translating reality English (ELECTRE), grey relational analysis (GRA), and simple additive weighting (SAW) method acting. In this discipline, hybrid multi-criteria decision-making models (AHP-TOPSIS, AHP-ELECTRE, AHP-GRA, and AHP-SAW) are presented and compared. Experimental results show that the offered hybrid the method in this study are consistent with each other and give the same ranking for the exception of the best supplier. It can be considered as a suitable recommendation for hospitals. Rađenović et al. [23] use AHP and TOPSIS to evaluate the efficiency of health information systems the provision of health caution services. The valuation of health information systems is shown in the case of the three highest commonly used computer software systems in electronic health care. This estimation is constructed on multi-criteria analysis of the health information systems competence using the AHP-TOPSIS technique acting. This technique is constructed on the familiar property and their particular 6 senses of value for all three software answers, separately defines the greatest ranked software solution. Meridian measured software solution of electronic health care is unnecessarily the greatest for the implementation and growing.

\section{METHODOLOGY}

This study aims to present integrated multi-criteria decisionmaking methods consisting of analytic hierarchy process (AHP), a technique for order preference by similarity to ideal solution (TOPSIS), and simple additive weighting (SAW) for determining the best vaccines for COVID19 to overcome the problem of choose vaccines and analysis the important criteria the affect in choose vaccines. This study consists of five steps given in Figure 1. In the first step, the literature was reviewed to determine the main criteria for evaluating and selecting the best vaccines, the easily and successfully solve the evaluation and selection problems, which are complicated and have multiple contradictory objectives or criteria. In many real-life decision-making problems, especially for supplier selection, MCDM methods are frequently used. A recent trend is using the MCDM methods integrating two or more methods. In this study, AHP, TOPSIS, SAW was used for vaccine selection methods are decision hierarchy was constructed. In the second step collect data about vaccines. In the third step, the weights of criteria and the decision matrix were found using the AHP method. In the fourth step, hybrid MCDM models (AHP, TOPSIS, and SAW) were used to select the best vaccines. Finally, the hybrid models were compared. MCDM is branch of operation research and show good performance in solve complex decision problem in our real life. MCDM methods can explained in the following section.

\subsection{Analytic Hierarchy Process (AHP)}

AHP Submitted by Thomas Saaty in 1980 [24], is an effective tool for dealing with complex decision making, and may support the decision-maker to set priorities and make the best decision. By reducing complex decisions to a series of pairwise comparisons, and then synthesizing the results. In addition, AHP combines a useful technique for checking the consistency of the decision maker's evaluations. AHP calculate consistency Index According to the formula $\mathrm{CI}=$ $(\lambda \max -n) /(n-1), \quad(\lambda \max :$ largest eigenvalue $)$, the consistency index (CI) is computed. Afterward, by taking random index (RI) values from Table 1 , the consistency ratio (CR) using the formula $\mathrm{CR}=\mathrm{CI} / \mathrm{RI}$ is computed for each matrix to measure whether the relative estimation is viable. values of $\mathrm{CR}$ should be less than or equal to 0.10 for each matrix. 


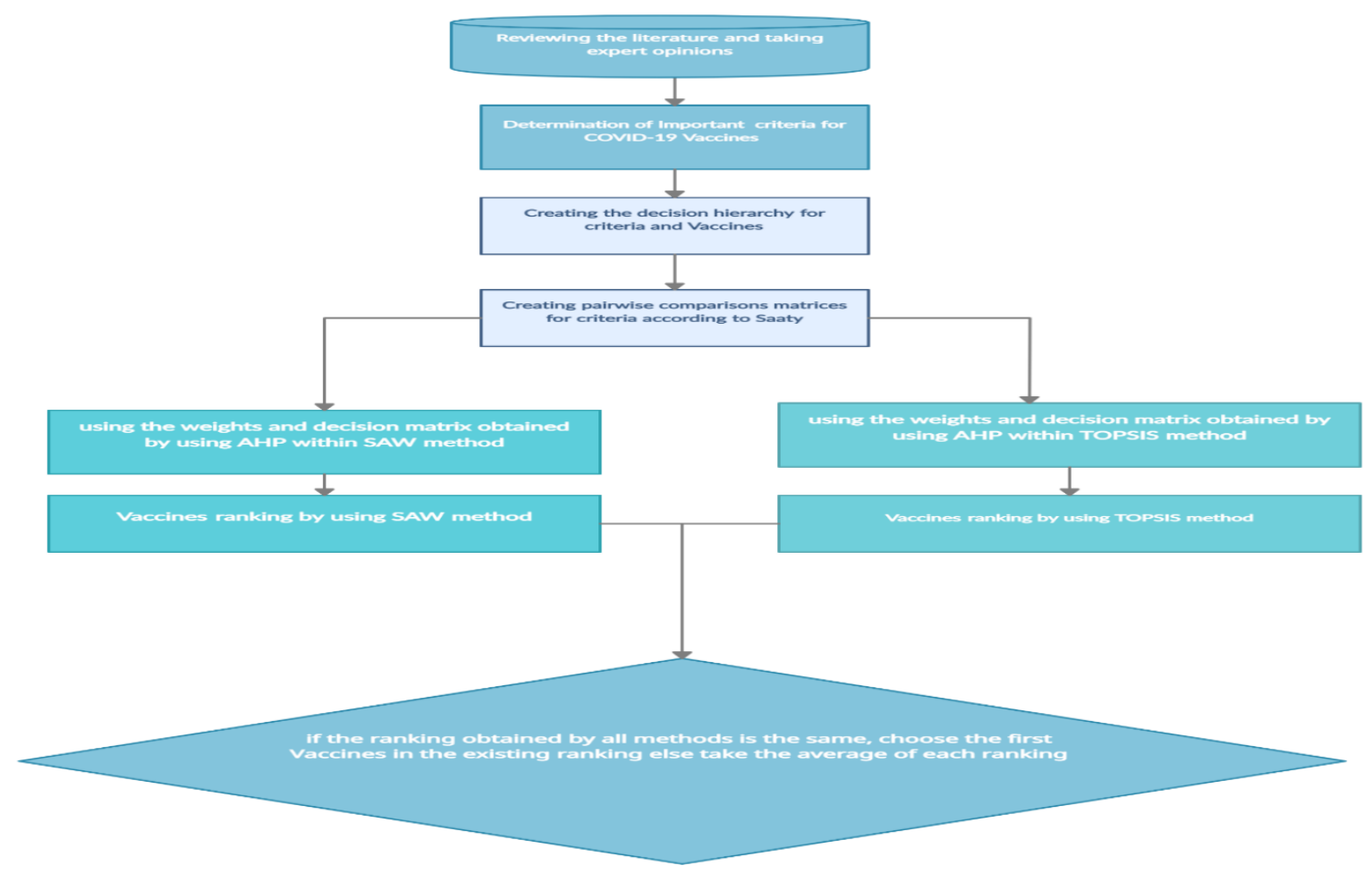

Fig1: Flow Chart of Proposed Methodology

\subsection{TOPSIS}

TOPSIS, proposed by Hwang and Yoon [25], is one of the MCDM methods. In this method, the positive ideal is produced of all best values obtainable from the criteria, whereas the negative ideal solution is produced of all worst values obtainable from the criteria. TOPSIS steps shown in Figure. 2, In general, the TOPSIS algorithm's process begins with the creation of a decision matrix that represents the satisfaction value of each criterion for each alternative. The values are then multiplied by the criteria weights, and the matrix is normalized using the appropriate normalizing technique. The positive-ideal and negative-ideal solutions are then determined, as well as the distance between each alternative.

\subsection{Simple Additive Weighting (SAW)}

The SAW technique is most likely the most popular Multiple Attribute Decision Making (MADM)[26]. Because of its simplicity, SAW is the most famous technique in taking care of MADM issues (W. Deni., 2013). SAW method is often known as the term of weighted summation International Journal of Pure and Applied Mathematics Special Issue 796method as well. The basic concept of SAW a method is to find a weighted sum of performance rating on each alternative in all attributes. 


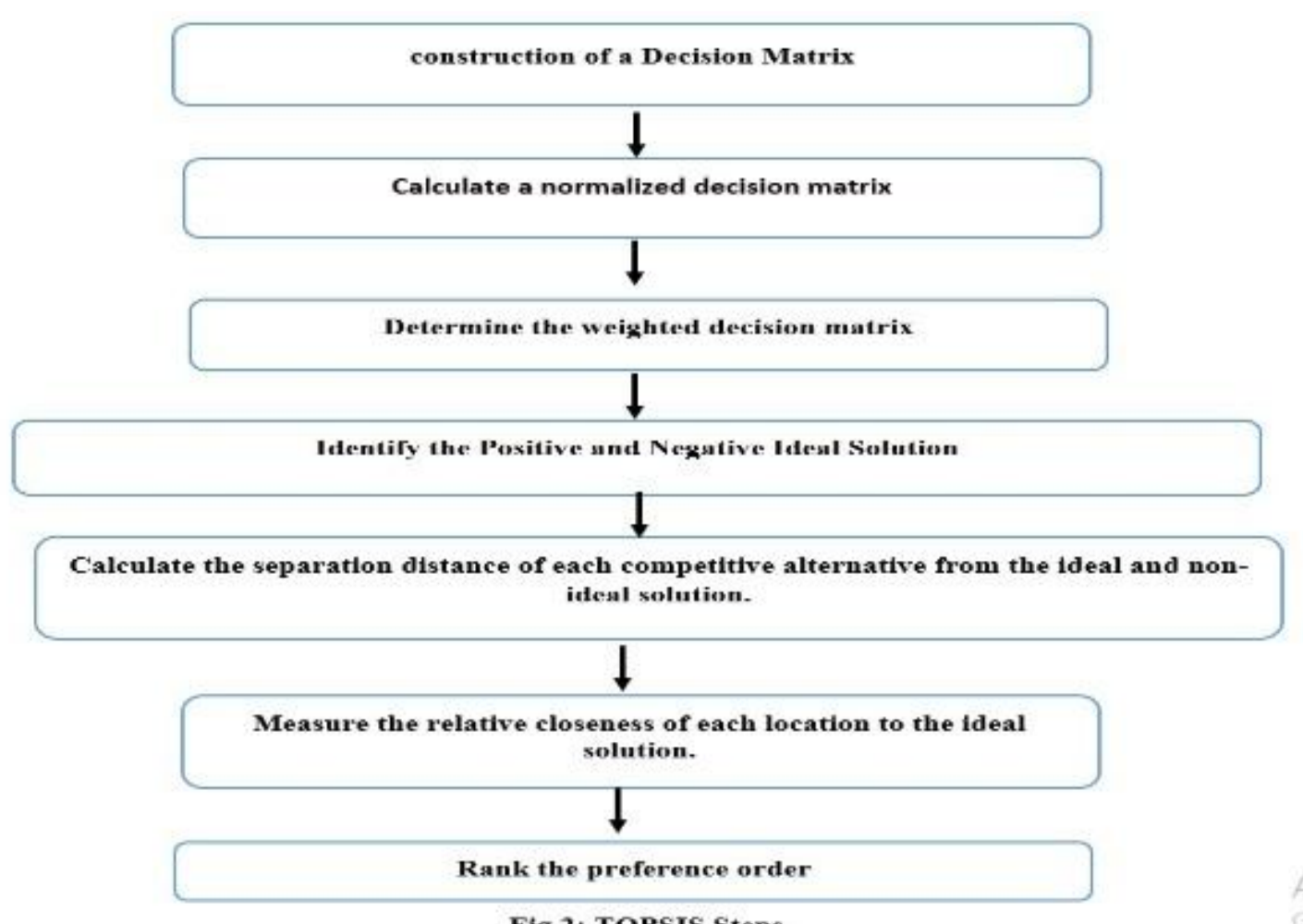

Fig.2: TOPSIS Steps

\section{EXPERIMENTAL RESULT}

In this section, we implement the hybrid MCDM methods to Ranking the Covid19 vaccines. We determined the criteria and construction of the decision hierarchy for Covid19 vaccines. In this paper data of vaccines are collected from the whole' webpages, obtain the main information such as available vaccines important criteria of vaccines we found important criteria are Safe, Cost, Efficacy, long-term protection, and safe for children. We contact the hierarchy for Covid19 vaccines in Figure 3 using AHP the hierarchy is consisting of three level, level one is the goal it ranking the three covid19 vaccines level two content five important criteria for covid19 vaccines finally level three contain three vaccines (Pfizer, Johnson \& Johnson's, AstraZeneca/Oxford), then we constructing pairwise comparison matrices between criteria and alternative we build code for AHP algorithm to apple to apply normalize matrix and get the final weights for the criteria the result as shown in Table 1 the Safe and safe for children get a big weight then efficiency then long term protection then cost. After this step we determine the weight matrix of the alternative using the AHP method decision matrix were calculated using AHP as shown in Table 1 the matrix show that Pfizer have the largest weight in safe and AstraZeneca/Oxford have the less weight in safe as show in table 1 Pfizer have largest weight in all criteria, Then we integrated MCDM methods first we integrated AHP And SWA, weights of criteria, and decision matrix obtained from AHP method was integrated into SAW methods to determine the best covid-19 vaccine as shown in Table 2 and Figure 4 the result shows that the order of vaccines are Pfizer then Johnson \& Johnson's then AstraZeneca/Oxford. then, we integrated TOPSIS and AHP as shown in Table 3 and Figure 5 the result shows that the order of vaccines is Pfizer then Johnson \& Johnson's. S then AstraZeneca/Oxford, finally we get average of two integrated methods the result show figure in 5 , so We conclude from this result that the best vaccine is Pfizer then Johnson \& Johnson's then AstraZeneca/Oxford.

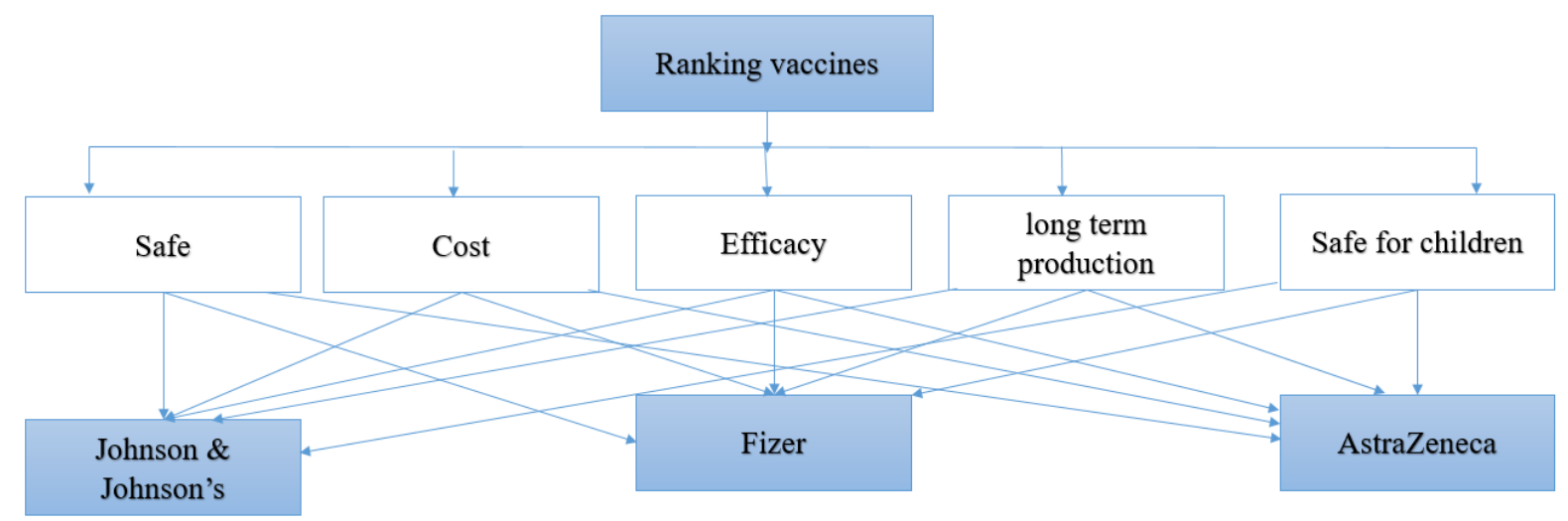

Fig3.: Decision hierarchy for Covid19 vaccines selection. 


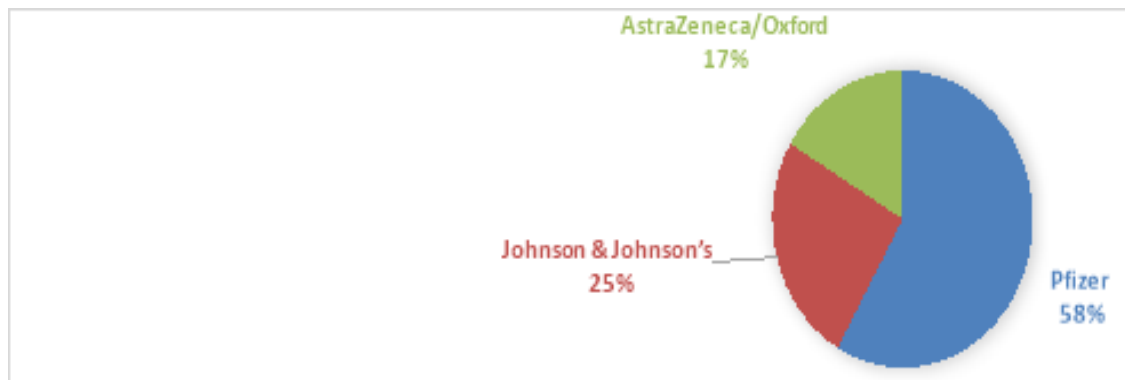

FIG4:AHP AND SWA RESULT

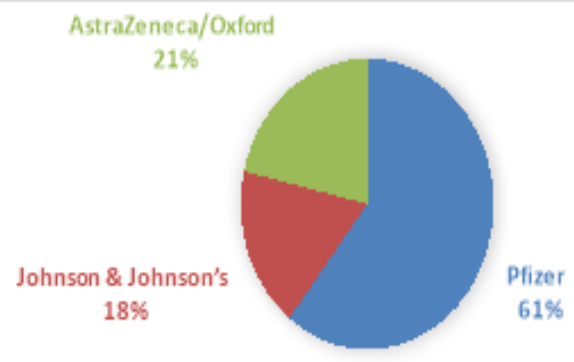

FIG5: AHP AND TOPSIS RESULT

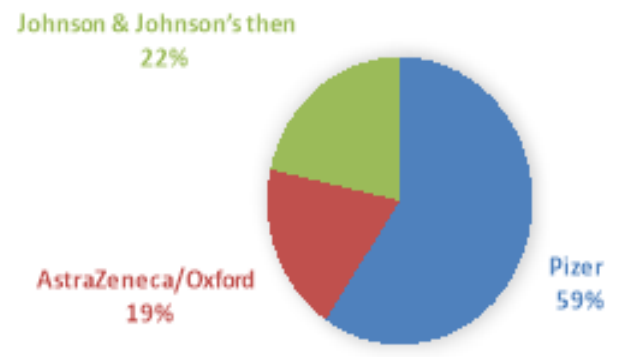

FIG6:FINAL RESULT

Table1: Decision matrix

\begin{tabular}{|c|c|c|}
\hline & Weighted score & Rank order \\
\hline Pfizer & 0.583082188 & 1 \\
\hline $\begin{array}{c}\text { Johnson \& } \\
\text { Johnson's }\end{array}$ & 0.251435587 & 2 \\
\hline $\begin{array}{c}\text { AstraZeneca/Oxf } \\
\text { ord }\end{array}$ & 0.165482225 & 3 \\
\hline
\end{tabular}


Table 2: Weighted score for each vaccines and ranking orders for AHP and SAW.

\begin{tabular}{|c|c|c|c|c|c|}
\hline & $\mathrm{S}+$ & S- & Total & CI & Rank Order \\
\hline Pfizer & 0 & $\begin{array}{c}0.23371 \\
5\end{array}$ & $\begin{array}{c}0.23371 \\
5\end{array}$ & 1 & 1 \\
\hline $\begin{array}{c}\text { AstraZeneca/Oxfor } \\
\text { d }\end{array}$ & $\begin{array}{c}0.18094 \\
6\end{array}$ & $\begin{array}{c}0.09887 \\
3\end{array}$ & 0.27982 & $\begin{array}{c}0.35334 \\
7\end{array}$ & 2 \\
\hline $\begin{array}{l}\text { Johnson \& } \\
\text { Johnson's }\end{array}$ & $\begin{array}{c}0.23371 \\
5\end{array}$ & $\begin{array}{c}0.09887 \\
3\end{array}$ & $\begin{array}{c}0.33258 \\
9\end{array}$ & $\begin{array}{c}0.29728 \\
5\end{array}$ & 3 \\
\hline
\end{tabular}

Table 3: Weighted score for each vaccines and ranking orders for AHP and TOPSIS

\begin{tabular}{|c|c|c|c|c|c|}
\hline & Safe & Cost & Efficiency & $\begin{array}{l}\text { long term } \\
\text { protection }\end{array}$ & $\begin{array}{l}\text { safe for } \\
\text { children }\end{array}$ \\
\hline Weight & 0.32179 & 0.016243379 & 0.2811353 & 0.059013068 & 0.321819615 \\
\hline Pfizer & 0.66949 & 0.666725949 & 0.5607449 & 0.648378664 & 0.5 \\
\hline AstraZeneca/Oxford & 0.08793 & 0.111106173 & 0.1697669 & 0.122029537 & 0.25 \\
\hline Johnson \& Johnson's & 0.24258 & 0.222167878 & 0.2694882 & 0.229591799 & 0.25 \\
\hline
\end{tabular}

\section{CONCLUSION}

COVID-19 begins in Wuhan China in Dec, 2019 1. It has diffusion rapidly and caused a global pandemic within a short period of time. The aim of this paper is help hospitals, clinics and organization they chose the suitable vaccines, the process of choose covid-19 vaccine is very difficult and need more analysis so, in this paper we integrated three MCDA methods AHP, SWA and TOPSIS to raking covid-19 vaccine, we get the information of vaccines from whole' webpages then we analysis this information using our prosed methodology the result show the best vaccine is Pfizer

\section{FUTURE WORK}

The results showed that MCDA are more effected in solving healthcare problem, multiple decision criteria are focusing on the future development and use of techniques to weight and score different decision criteria in healthcare. This article emphasizes the use and future benefit of MCDA. In future studies, other multi-criteria methods can be used to evaluate the performances of other tools in healthcare.

\section{REFERENCES}

[1] Abdel-Basst, Mohamed, Rehab Mohamed, and Mohamed Elhoseny. "<? covid19? > A model for the effective COVID-19 identification in uncertainty environment using primary symptoms and CT scans." Health Informatics Journal (2020): 1460458220952918.

[2] [Online]. Available: https://www.who.int. [Accessed 12 5 2021].WHO lists additional COVID-19 vaccine for emergency use and issues interim policy recommendations https://www.who.int/news/ Date:2021
Date accessed: May 12,2021

[3] Li, Qun, et al. "Early transmission dynamics in Wuhan, China, of novel coronavirus-infected pneumonia." New England journal of medicine (2020).

[4] Huang, Chaolin, et al. "Clinical features of patients infected with 2019 novel coronavirus in Wuhan, China." The lancet 395.10223 (2020): 497-506.

[5] Carlos, W. Graham, et al. "Novel Wuhan (2019-nCoV) Coronavirus." Am J Respir Crit Care Med (2020): P7-P8.

[6] Öztürk, Nzzz, et al. "Defining criteria weights by ahp in health technology assessment." Value in Health 20.9 (2017): A698.

[7] Saaty, Thomas L. "The analytic hierarchy process (AHP)." The Journal of the Operational Research Society 41.11 (1980): 1073-1076.

[8] Büyüközkan, Gülçin, Esin Mukul, and Elif Kongar. "Health tourism strategy selection via SWOT analysis and integrated hesitant fuzzy linguistic AHP-MABAC approach." Socio-Economic Planning Sciences 74 (2021): 100929.

[9] Amenta, Pietro, Antonio Lucadamo, and Gabriella Marcarelli. "On the choice of weights for aggregating judgments in non-negotiable AHP group decision making." European Journal of Operational Research 288.1 (2021): 294-301.

[10] Issa, Usama Hamed, Aly Ahmed, and Keizo Ugai. "A 
decision support system for ground improvement projects using gypsum waste case study: Embankments construction in Japan." Journal of Civil and Environmental Research 4.1 (2014): 74-84.

[11] Saivaew, Noppachai, and Suthep Butdee. "Decision making for effective assembly machined parts selection using fuzzy AHP and fuzzy logic." Materials Today: Proceedings 26 (2020): 2265-2271.

[12] Ruiz, H. S., et al. "GIS-AHP Multi Criteria Decision Analysis for the optimal location of solar energy plants at Indonesia." Energy Reports 6 (2020): 3249-3263.

[13] Wang, Fei, and Swee Pin Yeap. "Using magnetoadsorbent for methylene Blue removal: A decisionmaking via analytical hierarchy process (AHP)." Journal of Water Process Engineering 40 (2021): 101948.

[14] Issa, Usama H., Yehia H. Miky, and Fam F. AbdelMalak. "A decision support model for civil engineering projects based on multi-criteria and various data." Journal of Civil Engineering and Management 25.2 (2019): 100-113.

[15] McGhan, W. F., K. Vichaichanakul, and V. J. Willey. "PRM14 VALIDATING AN ONLINE CALCULATOR FOR EVALUATING HEALTH INTERVENTION OPTIONS USING THE ANALYTIC HIERARCHY PROCESS (AHP)." Value in Health 14.3 (2011): A148.

[16] Chauhan, Narvendra Singh, Pratap KJ Mohapatra, and Keshaw Prasad Pandey. "Improving energy productivity in paddy production through benchmarking-An application of data envelopment analysis." Energy conversion and Management 47.9-10 (2006): 1063-1085.

[17] Zavadskas, Edmundas Kazimieras, Zenonas Turskis, and Simona Kildiene. "State of art surveys of overviews on MCDM/MADM methods." Technological and economic development of economy 20.1 (2014): 165-179.
[18] Köksalan, M. Murat, Jyrki Wallenius, and Stanley Zionts. Multiple criteria decision making: from early history to the 21 st century. World Scientific, 2011.

[19] Keeney, Ralph L. "The art of assessing multiattribute utility functions." Organizational behavior and human performance 19.2 (1977): 267-310.

[20] Dhiman, Harsh S., et al. "Multi-criteria decision making approach for hybrid operation of wind farms." Symmetry 11.5 (2019): 675

[21] Suner, Asl1, et al. "Sequential decision tree using the analytic hierarchy process for decision support in rectal cancer." Artificial intelligence in medicine 56.1 (2012): $59-68$.

[22] Akcan, Serap, and Meral Güldeș. "Integrated multicriteria decision-making methods to solve supplier selection problem: a case study in a hospital." Journal of healthcare engineering 2019 (2019).

[23] Rađenović, Žarko, and Ivana Veselinović. "Integrated AHP-TOPSIS method for the assessment of health management information systems efficiency." Economic Themes 55.1 (2017): 121-142.

[24] Taherdoost, Hamed. "Decision making using the analytic hierarchy process (AHP); A step by step approach." International Journal of Economics and Management Systems 2 (2017).

[25] Hwang, Ching-Lai, and Kwangsun Yoon. "Methods for multiple attribute decision making." Multiple attribute decision making. Springer, Berlin, Heidelberg, 1981. 58191.

[26] NawindahNawindah, "Simple Additive Weighting (SAW) Mathematics Method for Warehouse Disaster Location," International Journal of Pure and Applied Mathematics, vol. 117, p. 15, 2017. 